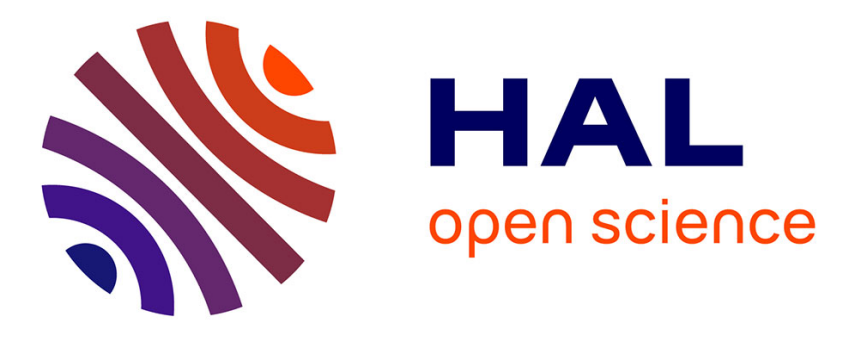

\title{
Predictive factors of length of inpatient treatment in anorexia nervosa
}

Luisa Strik Lievers, Florence Curt, Jenny Wallier, Fabienne Perdereau, Zoé

Rein, Philippe Jeammet, Nathalie Godart

\section{- To cite this version:}

Luisa Strik Lievers, Florence Curt, Jenny Wallier, Fabienne Perdereau, Zoé Rein, et al.. Predictive factors of length of inpatient treatment in anorexia nervosa. European Child and Adolescent Psychiatry, 2008, 18 (2), pp.75-84. 10.1007/s00787-008-0706-8 . hal-00478066

\section{HAL Id: hal-00478066 https://hal.science/hal-00478066}

Submitted on 30 Apr 2010

HAL is a multi-disciplinary open access archive for the deposit and dissemination of scientific research documents, whether they are published or not. The documents may come from teaching and research institutions in France or abroad, or from public or private research centers.
L'archive ouverte pluridisciplinaire HAL, est destinée au dépôt et à la diffusion de documents scientifiques de niveau recherche, publiés ou non, émanant des établissements d'enseignement et de recherche français ou étrangers, des laboratoires publics ou privés. 
Luisa Strik Lievers

Florence Curt

Jenny Wallier

Fabienne Perdereau

Zoé Rein

Philippe Jeammet

Nathalie Godart
Accepted: 19 June 2008

Published online: 22 September 2008

L. Strik Lievers, MD - F. Curt, MD, PhD

J. Wallier, MS - F. Perdereau, MD

Z. Rein, MS - Ph. Jeammet, MD, PhD

Dr. N. Godart, MD, PhD

Dept. of Psychiatry for Adolescents and

Young Adults

Faculté de Médecine

Site Institut Mutualiste Montsouris

Université Paris-Descartes

42 bd Jourdan

75014 Paris, France

J. Wallier, MS - F. Perdereau, MD

Z. Rein, MS - Ph. Jeammet, MD, PhD

Dr. N. Godart, MD, PhD

Unité 669 Paris-Sud Innovation Group in

Adolescent Mental Health: Troubles des

Conduites Alimentaires de l'Adolescent

Institut National de la Santé

et de la Recherche Médicale (INSERM)

Université Paris 5-Descartes

Paris, France

J. Wallier, MS · F. Perdereau, MD

Z. Rein, MS - Ph. Jeammet, MD, PhD

Dr. N. Godart, MD, PhD

Université Paris Sud Paris 11 Maison

de Solenn

97 Bd de Port Royal

Paris, France

\section{Predictive factors of length of inpatient treatment in anorexia nervosa}

Abstract Objective To identify clinical variables influencing the length of stay (LOS) of inpatient treatment for anorexia nervosa (AN). Method We analyzed structured clinical charts of 300 consecutive hospitalizations for $\mathrm{AN}$ in a specialized eating disorder unit. The sample included patients from 12 to 22 years old. Factors related to the patient and events occurring during the stay were investigated as possible predictors of LOS. Results Mean LOS was 135 days. The best model of linear regression revealed that the following factors were significantly related to LOS: duration of AN at admission, use of tube feeding during the stay, accomplishment of the therapeutic weight

\section{J.Wallier, MS}

Institute of Psychiatry

Kings College

London, UK contract and presence of a comorbid disorder. Conclusions The identification of factors influencing duration of stay, both at the outset and during the hospitalization, could help clinicians to optimize and individualize treatments, as well as increase patient and family compliance.

Key words anorexia nervosa length of stay - inpatient treatment

\section{Introduction}

Anorexia nervosa is a life-threatening disorder with a long average duration [28]. Treatment usually encompasses a wide variety of therapeutic ap- proaches. Among these approaches, inpatient treatment is considered the last resort, used only in cases of acute somatic and/or psychiatric need $[2,7]$. Traditionally, the length of stay (LOS) of such hospitalizations has been around 3 months in the UK [23], United States [18], and Switzerland [26], and between
Dr. N.Godart, MD, PhD ( $\varangle)$

Institut Mutualiste Montsouris

42 Bd Jourdan

75014 Paris, France

E-Mail: nathalie.godart@imm.fr 
2 and 7 months in Japan [20]. In the United States, LOS for anorexia nervosa has been dramatically reduced since the 1980s in favor of less intensive forms of care believed to be less costly and more costeffective [8, 30]. However, an excessively short LOS for inpatients with anorexia can be detrimental to care [30].

The need for inpatient treatment in the most severe cases of anorexia nervosa, and the equally real need to improve the cost-effectiveness of this type of treatment may be balanced by considering three questions: (1) Which factors influence LOS? (2) Can LOS be predicted at intake or during hospitalization? (3) Is there a safe way of reducing LOS, without consequences on relapse rates and prognosis? Identifying clinical variables involved in the prediction of LOS would make possible the elaboration of new treatment strategies focused on these elements. The objective would be to reduce LOS, and thereby the acute phase of the illness, avoiding its negative clinical and economic consequences. The ability to predict the duration of treatment, at the beginning and during the course of hospitalization would optimize treatment strategies for each patient, ameliorating compliance. Therefore, identifying predictors of LOS in anorexia is a crucial first step in safely reducing overall LOS and improving cost-effectiveness.

According to Huntley et al. [15], LOS of hospitalization for anorexia nervosa depends on three factor groups: factors related to the health care system, factors related to the patient, and factors related to treatment. Including more factors from each cluster group increases predictive power [6].

A Medline search revealed only two studies that directly examine factors influencing LOS in anorexia. Both studies consider only factors related to the patient. First, Nozoe et al. [20] evaluated possible predictors of outcome for AN for their relationship to LOS. This research concerned 55 subjects who completed the entire course of a behavior-oriented inpatient therapy in Japan. Second, Maguire et al. [19] published the results of a study regarding predictive factors of LOS in anorexia, based on data garnered from a multi-centre international database. Data on 218 hospitalizations (154 patients), in 5 medical centers (4 in Australia and 1 in New Zealand) were collected during a 20 -month period. In both studies, neither the history of illness nor the events during inpatient stay were considered as possible predictors of LOS. The only two published studies on this topic together revealed four predictors of LOS: minimum body weight after onset, age of admission, BMI at admission and number of previous inpatient admissions (See Table 1 for details).

Our clinical experience in an inpatient eating disorders unit for adolescents [9] suggests that addi- tional factors related to the patient, to the treatment and to the French health care system may be linked to a longer duration of inpatient care. In terms of clinical characteristics of these patients, before hospitalization, we believe that the following factors may be related to LOS: presence of child psychological disorders (enuresis, encopresis, anorexia, hyperphagia, rumination, history of suicide attempts, education level, socio-economic level, patient living away from home, alcohol and marijuana abuse, stealing, age at onset of anorexia, menstrual status (primary or secondary amenorrhea), duration of anorexia at admission, delay between first symptoms and first consultation, and distance from home to the hospital (selection of more difficult cases because our centre is specialized in treatment of the most severe cases). Furthermore, it is believed that the following factors concerning the patient during hospitalization are related to LOS: subtype of anorexia nervosa (restrictive or binge-purging), and presence of a comorbid obsessive compulsive, depressive or personality disorder during inpatient treatment. Additionally, our experience suggests that factors related to treatment and the French health care system during hospitalization, specifically tube feeding, transfer to intensive care, amplitude of the therapeutic contract (see "Methods" for details on the therapeutic contract; BMI at discharge, BMI at admission), and accomplishment of the therapeutic contract may lead to a longer LOS.

The purpose of this study is therefore to investigate whether these clinical factors, in addition to those patient factors already proven in research (minimum body weight after onset, age of admission, BMI at admission, and number of previous inpatient admissions), predict LOS.

\section{Method}

\section{Treatment ward description}

This study was carried out in the adolescent psychiatry department of the Institut Mutualiste Montsouris (IMM) in Paris. In this ward, inpatient treatment for anorexia nervosa is prescribed only as a last resort, as recommended by the APA [2]. Inpatient treatment is employed either because of the patient's physical state (i.e., emaciation, and somatic difficulties), or because of the patient's psychological condition (i.e., depression, suicide attempt or withdrawal). Treatment is multidisciplinary, including nurses, psychologists, physicians, physiotherapists and social workers, and is supervised by psychiatrists. During inpatient treatment, patients receive nutritional rehabilitation, 
Table 1 Predictors of LOS examined in prior research

\begin{tabular}{|c|c|c|}
\hline Study & Factors considered in univariate analyses & Factors significantly related to LOS \\
\hline Nozoe et al. [20] & $\begin{array}{l}\text { Sex } \\
\text { Poor social adaptation before onset (defined as not going to school or to work or being } \\
\text { unemployed) } \\
\text { Poor relationship between the patient and other family members before onset } \\
\text { Age at onset } \\
\text { Binge eating and/or vomiting after onset } \\
\text { Abuse of laxative and of diuretics after onset } \\
\text { Presence of severe bulimia, anxiety and/or personality disorders before onset } \\
\text { (retrospective diagnosis on chart) } \\
\text { Minimum body weight (percentage of ideal body weight) after onset } \\
\text { Duration of illness } \\
\text { History of inpatient treatment for AN or other physical disorders after onset } \\
\text { "Other" factors (age at admission, body weight at admission, number of previous } \\
\text { hospital treatments after onset, habitual stimulant abuse -alcohol, coffee and/or } \\
\text { cigarettes-, stealing, patients living away from family, absence for work or not going } \\
\text { to school after onset) }\end{array}$ & $\begin{array}{l}\text { Minimum body weight after onset } \\
\text { Age of admission }\end{array}$ \\
\hline Maguire et al. [19] & $\begin{array}{l}\text { Gender } \\
\text { Occupation } \\
\text { Education } \\
\text { Marital status } \\
\text { Age at onset of eating disorder (ED) } \\
\text { Age at admission } \\
\text { Minimum body weight after onset of ED } \\
\text { Body weight at admission } \\
\text { Previous treatment for an ED } \\
\text { Number of previous admissions } \\
\text { Binge purging subtype } \\
\text { Abuse of dieting products } \\
\text { Comorbid diagnosis } \\
\text { Drug use prior to admission } \\
\text { Menstrual status on admission } \\
\text { Presence of medical abnormalities (electrolytes, liver/renal enzymes, ECG) } \\
\text { Compliance with psychometric questionnaires on admission } \\
\text { Treatment site }\end{array}$ & $\begin{array}{l}\text { BMI at admission } \\
\text { Number of previous inpatient admissions }\end{array}$ \\
\hline
\end{tabular}

physical care and medication if necessary as well as individual and family psychological support. Tube feeding is used only when patients manifest severe physical symptoms of malnutrition, as well as an inability to eat to gain weight.

Intensive care indications are described in Table 2. The focal point of our standard inpatient treatment is the therapeutic contract [17] established between the patient, the family and the staff. The contract stipulates a lapse of time, called "separation," where contact between the patient and her normal social world (i.e., family, friends, school) is not allowed. We believe that the "separation" period allows the young patient to become acquainted with the treatment team, to think about her illness and difficulties, and to take a break from family conflicts. This contract is established during the pre-admission consultation and, with rare exceptions, is not changed during the hospital stay.

The contract focuses on two weight goals $[9,10]$ and it is therefore often called the "weight contract:" 1. The "target discharge weight," or the weight the patient must attain to be discharged from the unit. This weight is determined through consideration of
Table 2 Intensive care indications

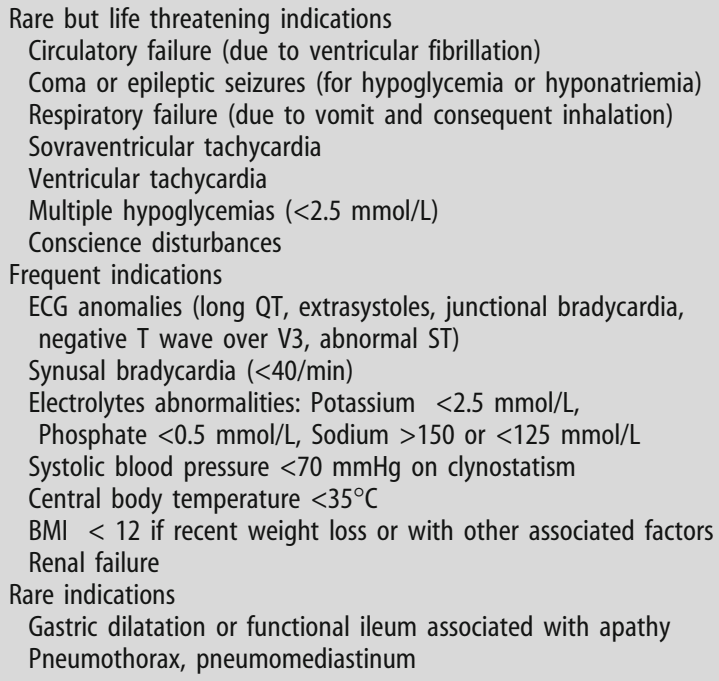

the patient's ideal medical body weight, the patient's maximum past weight, and the desires of the patient and her parents. 2. The "end of separation" or 
"intermediate" weight. This weight, situated within 2 $\mathrm{kg}$ of the mean of the final weight goal and the weight of the patient intake, is called the "end of separation weight" because the "separation" period ends when the patient attains this weight. Therefore, the duration of hospitalization is not defined at admission; rather, timing depends on the patient, who is discharged when final target weight is reached.

Weight objectives for inpatient treatment have not been defined by any eating disorder guidelines. Before becoming ill, our population of patients with anorexia has a large variability in weight, quite similar to that of the general French population [24] in terms of BMI (See graph for details). In our program, the ultimate discharge weight objective is a weight that will "allow the patient to re-enter normal life outside the hospital." Concretely, we define this objective by considering primarily the patient's weight before anorexia (or the patient's weight percentile before anorexia if the patient has grown substantially or if the patient has had anorexia for many years), as well as the patient's desired weight and her parents' desired weight for her. Unless the patient was extremely under- or overweight before anorexia, the weight before anorexia corresponds to the healthy, balanced weight that is most appropriate for that individual patient. Because we believe that returning to a weight that is close to this value during inpatient care is a reasonable objective [11], the team proposes this weight during the negotiation. The discharge weight is determined using concrete indications with the goal of finding a "reasonable" weight related to the patient's personal history.

\section{Participants}

Participants were selected from 300 consecutive hospitalizations of 12-22-year-old patients with eating disorders discharged from the adolescent and young adult psychiatry department of the IMM in Paris between May 1996 and February 2004. Inclusion criteria was a diagnosis of Anorexia Nervosa, according to DSM IV [3] criteria as confirmed by one of the senior psychiatrists of the team. Four participants met all diagnostic criteria except "amenorrhea for 3 months"; these patients were included regardless because most clinicians concur that amenorrhea is not indispensable for the diagnosis of Anorexia Nervosa [4, 29]. Three participants had a two month duration of amenorrhea, while one participant had a one month duration of amenorrhea.

Three patients were excluded from this research because a severe somatic disease complicated the symptoms (one patient with Diabetes Mellitus and two with Ewing Sarcoma). Further, 13 patients with eating disorders were excluded from this research because they did not meet diagnostic criteria for Anorexia Nervosa and had in most cases been hospitalized for comorbid mood disorders.

In addition, the 16 males treated as inpatients during this time were excluded from this study, because of their small number.

\section{Measures}

\section{Patient information questionnaire}

For each hospitalized patient, a structured chart, collecting clinical information was completed (483 items). The chart, created in 1996 by the last author (copies available on request), was inspired by the Maudsley database experience (i.e., systematic data collection on all hospitalized patients) [12] but includes different items, specifically socio-demographic information, information related to the medical state and clinical features, family and personal history at admission, specific symptoms, comorbidity, events during the time of hospitalization, plans for outpatient care at discharge, and also notes whether special interventions like tube feeding and transfer to intensive care were needed during care.

\section{Procedure}

The chart was completed for each patient by the resident child psychiatrist in charge of the patient's care. The first two parts were completed during the hospitalization and concern past history (individual and family) and events during the stay. The third part was completed at discharge and contains treatment information and future projects. The chart was then double checked for its contents and completeness, once by the senior resident and once by the chief psychiatrist responsible for the inpatient unit.

\section{Data analysis}

Qualitative variables were described using proportions and percentages. Proportions were compared using the chi-square test, with and without Yates' correction or Fisher's exact test, as required by the size of expected frequencies [5]. Quantitative variables were described using mean, standard deviation (SD) and range. The means of two independent groups were compared using Student $T$ tests or ANOVAs. A Bonferroni adjustment for multiple comparisons was carried out. The association between two quantitative variables was assessed using Pearson correlation coefficient $r_{\mathrm{s}}$ for continuous variables. All 
statistical tests were two-tailed; the level of significance was $\alpha=0.05$.

The relationship between LOS and possible predictors was investigated in two stages. First, this relationship was examined through univariate tests. Then, we tested the relationship between LOS (dependent variable) and the independent variables (selected through the results of the univariate tests and findings reported in the literature) using stepwise multiple linear regression).

Analyses were conducted using SPSS 10 (statistical package for social sciences).

\section{Results}

\section{Population description}

Our sample includes 268 hospitalizations of 213 female patients. Thirty-nine cases were repeat hospitalizations ( 1 patient was hospitalized 5 times, 4 were hospitalized 4 times, 5 were hospitalized 3 times, and 29 were hospitalized twice). The rate of previous hospitalizations for the same pathology was 0.58 hospitalizations $(\mathrm{SD}=1), 0.46$ hospitalizations $(\mathrm{SD}=0.86)$.

The mean age of our sample was 16.1 years $(\mathrm{SD}=1.6)$. Patients' average age of onset of anorexia was $15.3(\mathrm{SD}=1.8)$ years, with an average age of first consultation of $15.5(\mathrm{SD}=1.9)$ years. The average duration of illness was 20.39 ( $S D=17.2)$ months.

Out of 268 hospitalizations, $217(81 \%)$ were for Anorexia Nervosa- restrictive type and 51 (19\%) were for Anorexia nervosa- purging type. In our population, 40 hospitalizations (14.9\%) were of patients presenting primary amenorrhea. Out of the 268 hospitalizations, $32(12.7 \%)$, were of patients taking oral contraceptives, of whom three presented primary amenorrhea. The average duration of secondary amenorrhea was 17.24 months $(\mathrm{SD}=14.38)$.

The mean BMI at admission was $13.46(\mathrm{SD}=1.26)$ similar to the minimal BMI after onset of anorexia $(\mathrm{M}=13.13 ; \mathrm{SD}=1.3)$, with a lifetime maximum $\mathrm{BMI}$ of $19.72(\mathrm{SD}=2.68)$. There was a mean difference of 4.1 points between BMI at discharge and BMI at admission. The mean "end of separation" BMI was $15.6(\mathrm{SD}=1)$, on average 2.1 ( $\mathrm{SD}=0.9)$ BMI over BMI at admission. The mean BMI at discharge was $17.35(\mathrm{SD}=1.4$, Range $=11.7-20.4)$, while the mean contract discharge weight was $17.63(\mathrm{SD}=1)$. For 196 hospitalizations $(76.1 \%)$ the contract was fulfilled (the patient was discharged once reached the weight target); in 72 (33.9\%) it was not. For those 72 discharges, $27 \%$ were discharged during the first part of the contract ("separation") and $73 \%$ in the second part, and we found no significant difference for LOS be- tween patients discharged during the first and second parts of their contracts (139 vs. 190 days). The mean LOS for all patients was 135 days $(S D=97)$.

During inpatient treatment, patients were transferred to intensive care in 47 hospitalizations (17.5\%) and $73(27 \%)$ needed tube feeding. During hospitalization patients presented comorbid personality disorders $(26.1 \%)$, mood disorders $(23.9 \%)$ and anxiety disorders (9\%). History of marijuana use, stealing and alcohol abuse were reported in only 6, 8 and 11 hospitalizations, respectively. The rate of suicide attempts was $12.6 \%$.

Socio-demographic questionnaires revealed that $77.2 \%$ of patients went to school, $22 \%$ to college and the rest of the patients had stopped school. They mostly lived in Paris (29.1\%), the close suburbs $(31.7 \%)$ or the further suburbs $(34 \%)$; only $5.2 \%$ lived in other French regions or abroad. A majority of participants $(87 \%)$ lived with one or both their parents. Divorce (12\%) and separation (12\%) percentages of the parents were notably low; in the general population of metropolitan France there is a $42.5 \%$ divorce rate [16].

Out of the 268 hospitalizations, $22(8 \%)$ were of participants whose fathers worked in agriculture, or as artisans, shopkeepers or heads of business. Seventy-eight $(27 \%)$ had fathers working as blue collar workers or employees. One hundred and sixty-two $(60.5 \%)$ had fathers working in high-level professional jobs (managers, intellectual professions).

\section{Predictive factors of LOS}

We first tested the link between possible predictive variables (those reported in previous research and our hypothesized variables; see "Introduction") and LOS with univariate tests and then conducted a multiple linear regression analysis.

\section{Univariate analyses}

First, we checked whether or not there was an association between each of the possible predictors defined in the introduction and LOS using univariate tests (see Tables 3,4). The following factors were related to LOS; duration of anorexia $(r=0.127$; $P=0.038)$, tube feeding $(P=0.000)$, transfer to intensive care $(P=0.012)$ accomplishment of the therapeutic weight contract $(P=0.001)$, and presence of a comorbid disorder during hospitalization (LOS for each comorbid group compared to the noncomorbid group, $P=0.000)$. Each comorbid group had a significantly longer LOS than the group without any comorbid disorders, with no significant differences in LOS found between the three comorbid dis- 
Table 3 Possible qualitative predictors of LOS

\begin{tabular}{|c|c|c|}
\hline & Mean LOS (days) $\pm S D$ & $P$ value \\
\hline Tube feeding & $\begin{array}{l}\text { No } 117 \pm 84 \\
\text { Yes } 180 \pm 114\end{array}$ & 0.000 \\
\hline Accomplishment of the contract & $\begin{array}{l}\text { Yes } 120 \pm 78 \\
\text { No } 180 \pm 132\end{array}$ & 0.001 \\
\hline Comorbidity yes/no & $\begin{array}{l}\text { Yes } 120 \pm 78 \\
\text { No } 99 \pm 75\end{array}$ & 0.000 \\
\hline $\begin{array}{l}\text { Needing intensive care treatment } \\
\text { during hospitalization }\end{array}$ & $\begin{array}{l}\text { Yes } 167 \pm 103 \\
\text { No } 127 \pm 94\end{array}$ & 0.012 \\
\hline Anorexia sub- type & $\begin{array}{l}\text { Restrictive } 131 \pm 96 \\
\text { Binge purging } 148 \pm 99\end{array}$ & 0.266 \\
\hline History of stealing & $\begin{array}{l}\text { Yes } 150 \pm 81 \\
\text { No } 134 \pm 97\end{array}$ & 0.648 \\
\hline Marijuana abuse & $\begin{array}{l}\text { Yes } 178 \pm 61 \\
\text { No } 133 \pm 97\end{array}$ & 0.264 \\
\hline Alcohol abuse & $\begin{array}{l}\text { Yes } 122 \pm 77 \\
\text { No } 135 \pm 98\end{array}$ & 0.666 \\
\hline Distance from hospital & $\begin{array}{l}\text { Paris, PC } 126 \pm 98 \\
\text { GC, Province } 146 \pm 94\end{array}$ & 0.098 \\
\hline Education & $\begin{array}{l}\text { Middle or high schooler } \\
\quad 140 \pm 102 \\
\text { College student } 117 \pm 74\end{array}$ & 0.065 \\
\hline Childhood psychological disorders & $\begin{array}{l}\text { Yes } 133 \pm 101 \\
\text { No } 134 \pm 97\end{array}$ & 0.927 \\
\hline Lives with her parents & $\begin{array}{l}\text { Yes } 135 \pm 101 \\
\text { No } 131 \pm 67\end{array}$ & 0.090 \\
\hline Menstrual status & $\begin{array}{l}\text { Amenorrhea I } 125 \pm 92 \\
\text { Amenorrhea II } 135 \pm 97\end{array}$ & 0.542 \\
\hline Socio economic level (1) & $\begin{array}{l}\text { I } 108 \pm 23^{* *} \\
\text { II } 139 \pm 103 \\
\text { III } 128 \pm 92\end{array}$ & 0.532 \\
\hline
\end{tabular}

(1) I = Agricultural, artisan, shopkeepers or heads of business

$\|$ = As blue collar workers or employees

III = High-level professional jobs (managers, intellectual professions)

${ }^{*} F$ value $=0.821$

Table 4 Possible quantitative predictors of LOS

\begin{tabular}{lrr}
\hline & $\begin{array}{c}\text { Correlation } \\
\text { coefficient }\end{array}$ & $P$ value \\
\hline Duration of anorexia & 0.127 & 0.038 \\
Age at onset & -0.087 & 0.157 \\
Amplitude of contract (BMI discharge-BMI admission) & 0.104 & 0.090 \\
BMl admission & -0.099 & 0.105 \\
Age at admission & -0.035 & 0.564 \\
Minimal BMI after onset & -0.082 & 0.182 \\
Nr of previous hospitalizations for anorexia & 0.100 & 0.103 \\
Delay between onset of illness and first treatment & -0.101 & 0.116 \\
\hline
\end{tabular}

(1) I = Agricultural, artisan, shopkeepers or heads of business

II = As blue collar workers or employees

III = High-level professional jobs (managers, intellectual professions)

order groups [Mood disorders: 141 days $(\mathrm{SD}=77)$; Anxiety disorders: 174 days $(S D=142)$; Personnality disorders: 171 days $(S D=103)$. Most $(22 / 24 ; 91.6 \%)$ of the patients diagnosed with an anxiety disorder had obsessive compulsive disorder. The duration of the first part of the hospital stay, "separation," was significantly correlated to the second part $(r=0.24$
Table 5 Predictors of LOS

\begin{tabular}{lrr}
\hline & \multicolumn{1}{l}{ B } & $P$ \\
\hline Duration of anorexia & 7,491 & 0.038 \\
Use of tube feeding & 49,500 & 0.000 \\
Comorbidity (yes/no) & 19,775 & 0.000 \\
Accomplishment of the therapeutic weight contract & $-50,281$ & 0.000 \\
\hline
\end{tabular}

$P=0.000$ ), with patients who took longer to reach their "end of separation weight" also taking longer to reach their hospital discharge weight. Notably, there was no significant difference in LOS between patients over and under 18 years, suggesting that patients over 18 , who do not need their parents' consent for discharge, are not more likely leave hospital earlier. In addition, the amplitude of the weight contract (BMI at discharge-BMI at admission), which reflects the amount of weight to be gained during the hospitalization, is not related to LOS.

\section{Linear regression}

The best model obtained (the model that included all variables found to be significantly related to LOS in the univariate analyses as well as the variables identified in the literature) revealed that the duration of anorexia $(P=0.038)$, the use of the tube feeding $(P=0.000)$, adherence to the therapeutic weight contract $(P=0.000)$, and an observed comorbid disorder during hospitalization $(P=0.000)$ were significantly related to LOS, accounting for $24.6 \%$ of the variance $\left(R^{2}=0.246\right)$. LOS increased in direct correlation to the duration of anorexia, the use of tube feeding and an observed comorbid disorder and decreased in relation to adherence to the therapeutic contract (see Table 5 below). The same analyses were conducted including the amplitude of the contract as an independent variable. The results did not change.

\section{Discussion}

The present research examined possible predictors of LOS for anorexia. In doing so, this study considered many variables concerning the patient before treatment, as had the few previous studies on the subject; however, in addition, this research examined variables related to the patient during hospitalization and the French health care system.

Our findings show that LOS is explained by the duration of anorexia at admission, the use of tube feeding during the stay, the presence of a comorbid disorder during hospitalization and the accomplishment of the therapeutic weight contract. Only one of 
these factors (duration of anorexia) preceded the hospitalization; the three others were observed during the inpatient stay, suggesting that LOS can be most accurately predicted during hospitalization.

The relationship between duration of anorexia history and LOS has been frequently noted as an important prognostic factor for the evolution of the illness [14, 21, 25, 27]. A longer illness is likely to be more psychopathologically complicated and will thus be less sensitive to therapeutic intervention[1]. Such patients also are more likely to have a longer history of ineffective treatment attempts. Although Nozoe et al. [20] did not find a link between these variables and LOS, some characteristics of that research may explain why: 1 . The sample size was small, 2 . It evaluated less than four patients per year, treated between 1972 and 1988, a 16 year period during which treatment may have evolved. 3. Patients were described and diagnosed retrospectively. 4 . The patient group included only 5 males and 50 females, only $49 \%$ (55/112) of hospitalized patients, and the patients included spanned a wide age range (mean 20 years old, varying from 13 to 37). 5. Drop-out and discharges before completing the program were not considered. Our research finding that a longer duration of anorexia leads to a longer LOS lends support to Agras's theory [1]. Identifying patients with a long history of illness at admission will enable clinicians to prepare the patient and her family for the length of treatment. In this way, clinicians may improve patient and family adhesion to a long treatment program.

Our findings also suggest that the prediction of LOS needs to be re-considered during hospitalization, since patient characteristics during hospitalization and factors related to treatment also predicted LOS in our study. First, our research shows that the use of tube feeding (27.2\% of hospitalizations) is related to longer hospitalizations. To our knowledge this relationship has not yet been considered in research. In fact the only study to our knowledge on this topic concerned nocturnal feeding in a pediatric ward [22]. That study suggested a decreased LOS; however, while use of feeding tubes does lead to faster weight gain, the need for tube feeding suggests resistance to treatment and the incapacity to gain weight by eating. This resistance is independent of the duration of illness, of comorbid disorders and of therapeutic contract completion. Perhaps this resistance means that the patient is psychologically unable to begin to gain weight on personal initiative; and/or perhaps, it is a sign of an inadequate therapeutic alliance with the patient and/or her parents.

Transfer to intensive care (17.5\% of patients) was also shown to predict a longer LOS. The need for intensive care does not necessarily indicate low weight or weight gain stagnation, as admission could also be due to severe medical conditions, such as cardiac or electrolytic symptoms. These medical situations would correspond either to patients who vomit very frequently, or to patients who have rapidly lost dangerously large quantities of weight. Both situations are related to grave cases of anorexia, and the severity of these cases is reflected in LOS.

Further, accomplishment of the therapeutic weight contract used in our ward was significantly related to LOS. Patients who do not fulfill the contract (that is, those for whom the hospitalization is interrupted before reaching the target weight), were found to have longer LOS. The rupture of the contract usually occurs in a late phase of the stay $(73 \%$ in the second part vs. $27 \%$ in the first part). This finding is linked to the treatment team's use of the weight contract; only patients who have experienced long hospitalizations without weight gain are discharged before attaining their target weight [10]. It would be interesting to study the clinical characteristics of the patients that do not fulfill the contract (in our population, 24\%) because their identification at the beginning of inpatient treatment would allow us to develop other treatment strategies more appropriate for them. Furthermore, we found that the duration of the first part of the hospitalization, "separation," was significantly linked with the second part. This finding further suggests that LOS should be re-evaluated during hospitalization: with this information, patient treatment can be modified during the hospital stay and clinicians can help adapt patient expectations.

We also found a strong relationship between the presence of a comorbid disorder during hospitalization after re-nutrition and LOS: specifically, we found that the mean LOS for a patient with anorexia and a comorbid mood disorder, anxiety disorder or personality disorder is longer than for anorexia with no comorbid disorder. Nozoe et al. [20] and Maguire et al. [19] also hypothesized that the presence of a comorbid disorder would affect LOS but did not demonstrate this. We did not, however, find significant differences between diagnostic groups in terms of LOS. Anorexia, when complicated by a secondary diagnosis, should not be the only target of treatment and requires longer hospitalizations because the presence of a comorbid disorder slows weight gain even further. Some inpatient treatment programs for anorexia exclude patients without sufficient weight gain after just a few weeks. The presence of a comorbid disorder needs to be more thoroughly considered in patients resistant to traditional treatment programs so that appropriate treatment can be focused on these problems before concluding that such patients are untreatable. Further, it is important to note that the presence of a comorbid disorder is a negative prognostic factor for the evolution of anor- 
exia $[13,26,28]$. Therefore, in light of our findings that these patient and treatment characteristics during hospitalization predict LOS, we believe that it is essential that these factors be considered during inpatient treatment in order to adapt treatment and hopefully, minimize LOS.

Some results did not support our hypotheses or previous research findings. First, our findings that the minimal BMI after onset of anorexia, the BMI at admission, and the amplitude of weight contract (or weight to be gained) were not significantly linked to LOS did not support those of Nozoe et al. [20] and Maguire et al. [19]. Differing therapeutic approaches may account for these divergences. The Nozoe et al. study concerned patients treated with behavior therapy, for whom the timing of the inpatient stay depended strictly upon weekly rates of weight gain. Therefore, a patient with a lower BMI at admission was likely to need a longer hospitalization. Our psychodynamically-oriented treatment allows patients to determine the timing of weight gain. The patient does this with the help of the intensive psychological and rehabilitative work done during the stay. A patient with a very low BMI at outset might therefore gain weight more quickly than one with a higher BMI at the time of admission. A number of factors, including different psychopathology (including comorbid disorders) and the degree of therapeutic alliance with the patient and her family, may explain individual differences in weight-gain curves. Factors explaining these differences should be examined in future research.

Furthermore, our findings did not support a relationship between age at onset and at admission and LOS. Although our results would concur with those of Maguire et al. [19], Nozoe et al. [20] found positive correlations for both age at onset and LOS and age at admission and LOS. One explanation for this difference is that our sample was on average younger (16 vs. 20 years old), with a younger age of onset (15 vs. 17 years old), than that of Nozoe et al. Furthermore, this age difference would also explain why the number of previous hospitalizations was not found to be linked to LOS in our sample: our patients were young with short clinical histories.

Also in contrast to our hypotheses, we did not demonstrate relationships between LOS and the delay between onset of symptoms and first psychiatric consultation (variable not present in the literature) or between LOS and the type of anorexia, or finally, between LOS and elements of personal history (level of education, positive anamnesis for psychiatric disturbances or diseases, for stealing, violence or alcohol abuse). Those factors have been partially examined in the literature, although their relationship to LOS has not been established through multivariate analysis:
Maguire et al. found a positive correlation with the number of years of education and Nozoe et al. found positive correlations for the variables "poor social adaptation," "history of stealing" and "habitual stimulant abuse." Finally, we did not find a relationship between LOS and the distance from the hospital (as found by Maguire et al.).

The findings of this research are noteworthy for two reasons in particular. First, this research has identified a new factor preceding the hospitalization that may predict LOS (i.e., duration of illness). Second, this prospective study is the first to also consider therapeutic changes occurring during the hospitalization. Our results are strengthened by our low drop-out rate $(24 \%$ vs. $49 \%$ for Nozoe et al. [20]; of the $24,50 \%$ staff decision, and $50 \%$ parent decision). In addition, because of our young sample [we admit mainly young girls before 18 (under 22)], hospitalization can be interrupted only with parental agreement, reducing drop-out bias. Like Maguire [19], we believe that determining LOS is a pragmatic consideration in the development of inpatient programs. We also believe that identifying predictive factors of LOS is important to help clinicians better inform patients and their families about the potential for a long hospitalization, which should increase adherence to treatment and improve therapeutic alliance.

\section{Limitations}

These results apply to a sample of patients cared for in the French health system with a specific treatment protocol. Therefore, these results can not be generalized to all populations. Nevertheless, this research has identified potential therapeutic targets for improving inpatient care, specifically comorbid disorders. Furthermore, the predictive factors identified by this research may be relevant for other teams and health systems because of the similarities found between Nozoe's and Maguire's results and our own. It might appear that another potential limitation of this research was our method of contract or weight-goal determination; because two patients with the same height and age do not necessarily have the same weight goal, it could appear that the variability of the amount of weight to be gained would affect LOS. It should be noted that the amplitude of the contract (the amount of weight to be gained) was taken into account in the multivariate analyses, voiding this possibility.

Although our regression model explained only $24.6 \%$ of the variance of LOS, our results were consistent with our clinical hypotheses. However, our results need to be confirmed by other studies which 
may identify factors that further contribute to the model.

In addition, these results emphasize the fact that variables may have differenc effects on LOS as a function of the reasons for their use. For example, systematic use of feeding tubes may reduce LOS; however, when feeding tubes are prescribed because all other techniques have failed, their use may predict an increase in LOS.

\section{Conclusions}

Identifying clinical variables involved in the prediction of length of inpatient treatment could help us to develop new treatment strategies focused on these elements. Furthermore, the ability to identify factors that influence LOS at its beginning and during its course, would optimize treatment strategies for each patient, enhancing compliance. In this way, LOS and the acute phase of the illness could be minimized, limiting negative clinical and economic consequences.

However, this research also highlights the need for longer hospitalizations in specific cases. Specifically, longer hospitalizations may be necessary for cases in which the patient needs to spend more time in the hospital to attain a sufficient discharge weight, which is a predictor of a good long-term prognosis. We hope that by identifying factors that predict LOS, such as the presence of a comorbid disorder, and targeting these factors for treatment, we will be able to reduce LOS. However, perhaps we also need to concentrate our efforts on convincing financial decision makers of the necessity and long-term cost effectiveness of longer hospitalizations in more complicated cases. In order to accomplish these goals, future research should examine the efficacy of such hospitalizations and measure the impact of early treatment for comorbid disorders on LOS.

\section{References}

1. Agras WS, Brandt HA, Bulik CM, Dolan-Sewell R, Fairburn CG, Halmi KA, Herzog DB, Jimerson DC, Kaplan AS, Kaye WH, Le Grange D, Lock J, Mitchell JE, Rudorfer MV, Street LL, Striegel-Moore R, Vitousek KM, Walsh BT, Wilfley DE (2004) Report of the national institutes of health workshop on overcoming barriers to treatment research in anorexia nervosa. Int J Eat Disord 35:509-521

2. American Psychiatric Association (2000) Practice guideline for the treatment of patients with eating disorders (revision). Am J Psychiatry 157:1-39

3. American Psychiatric Association (1994) Diagnostic and statistic manual of mental disorders, 4th edn. American Psychiatric Association, Washington DC

4. Cachelin FM, Maher BA (1998) Is amenorrhea a critical criterion for anorexia nervosa? J Psychosom Res 44:435-440

5. Cochran WG (1954) Some methods for strengthening the common $\mathrm{chi}^{2}$. Tests Biometr 10:417-451

6. Creed F, Mbaya P, Lancashire S, Tomenson B, Williams B, Holme S (1997) Cost effectiveness of day and inpatient psychiatric treatment: results of a randomised controlled trial. Br Med J 314:1381-1385

7. Fairburn CG, Harrison PJ (2003) Eating disorders. Lancet 361:407-416
8. Garner DM, Needleman LD (1997) Sequencing and integration of treatments. In: Garner DM, Garfinkel PE (eds)Handbook of treatment of eating disorders, 2nd edn. Guidford Press, New York, pp 50-63

9. Godart N, Atger F, Perdereau F, Agman G, Rein Z, Corcos M, Jeammet Ph (2004) Treatment of adolescent patients with eating disorders: description of a psychodynamic approach in clinical practice. Eat Weight Disord 9:224-227

10. Godart N, Perdereau F, Gales O, Agman G, Deborde AS, Jeammet P (2005) The weight contract during the hospitalization of anorexic patients. Arch Pediatr 12:1544-1550

11. Golden NH, Jacobson MS, Schebendach J, Solanto MV, Hertz SM, Shenker (1997) Resumption of menses in anorexia nervosa. Arch Pediatr Adolesc Med 151:16-21

12. Goodman R, Simonoff E (1991) Reliability of clinical rating scale by trainee child psychiatrists: a research note. J Child Psychopathol Psychiatry 32:551555

13. Herpertz-Dahlmann BM, Wewetzer C, Schulz E, Remschmidt H (1996) Course and outcome in adolescent anorexia nervosa. Int J Eat Disord 19:335-345

14. Herzog DB, Keller MB, Lavori PW (1988) Outcome in anorexia nervosa and bulimia nervosa: a review of the literature. J Nerv Ment Dis 176:131-143
15. Huntley DA, Cho DW, Christman J, Csernansky JG (1998) Predicting length of stay in an acute psychiatric hospital. Psychiatr Serv 49:1049-1053

16. Institut National d'études démographiques: divorces en France métropolitaine (2003); Available at: http://wwwinedfr/fr/pop_chiffres/ france/mariages_nuptialite/divorces/ Accessed September 2006; 15

17. Jeammet Ph (1984) Contrat et contraintes Dimensions psychologiques de l'hospitalisation dans le traitement de l'anorexique. Psychol Fr 29:137-143

18. Kahn C, Pike KM (2001) In search of predictors of dropout from inpatient treatment for anorexia nervosa. Int $\mathrm{J}$ Eat Disord 30:237-244

19. Maguire S, Surgenor LJ, Abraham S, Beumont P (2003) An international collaborative database: its use in predicting length of stay for inpatient treatment of anorexia nervosa. Aust $\mathrm{N}$ Z J Psychiatry 37:741-747

20. Nozoe S, Soejima Y, Yoshioka M, Naruo T, Masuda A, Nagai N, Tanaka $\mathrm{H}$ (1995) Clinical features of patients with anorexia nervosa: assessment of factors influencing the duration of inpatient treatment. J Psychosom Res 39:271-281

21. Ratnasuriya RH, Eisler Y, Smukler GI, Russel GFM (1991) Anorexia nervosa: outcome and prognosis factors after twenty years. Br J Psychiatry 158:495502 
22. Robb AS, Silber TJ, Orrell-Valente JK, Valadez-Meltzer A, Ellis N, Dadson MJ, Chatoor I (2002) Supplemental nocturnal nasogastric refeeding for better short-term outcome in hospitalized adolescent girls with anorexia nervosa. Am J Psychiatry 159(8):1347-1353

23. Robinson P (1993) Treatment for eating disorders in the United Kingdom. Part I. A survey on specialist services. Eur Eat Disord Rev 1:4-9

24. Rolland-Cachera MF, Cole TJ, Sempe $\mathrm{M}$, Tichet J, Rossignol C, Charraud (1991) A body mass index variations: centiles from birth to 87 years. Eur J Clin Nutr 45(1):13-21
25. Steinhausen HC, Rauss-Mason C, Seidek R (1991) Follow up studies of anorexia nervosa: a review of four decades of outcome research. Psychol Med 81:447-454

26. Steinhausen HC, Seidel R (1993) Outcome in adolescent eating disorders. Int J Eat Disord 14:487-496

27. Steinhausen HC (2002) The outcome of anorexia nervosa in the 20th century. Am J Psychiatry 159:1284-1293

28. Strober M, Freeman R, Morrell W (1997) The long-term course of severe anorexia nervosa in adolescents: survival analysis of recovery, relapse and outcome predictors over $10-15$ years in a prospective study. Int J Eat Disord $22: 339-360$
29. Watson TL, Andersen AE (2003) A critical examination of the amenorrhea and weight criteria diagnosing anorexia nervosa. Acta Psychiatr Scand 108:161162

30. Wiseman CV, Sunday RS, Klapper F, Harris WA, Halmi KA (2001) Changing patterns of hospitalisation in eating disorders patients. Int J Eat Disord 30:69-74 